\title{
Effect of Alkaline Solution on Different Types of Fly Ash of GPC.
}

\author{
S. L. Hake ${ }^{1}$, O. D. Waghmare ${ }^{2 *}$ \\ ${ }^{1}$ Associate Professor, DVVP COE Ahmednagar, Maharashtra, India. \\ ${ }^{2}$ PG Students, DVVP COE Ahmednagar.
}

*Corresponding Author: O. D. Waghmare, PG Students, DVVP COE Ahmednagar.

\begin{abstract}
Cement industry plays major role for emission of greenhouse gasses. So, there is need for manufacturing of environmental friendly concrete. Geopolymer concrete helps in reduce global warming as well as fly ash disposal problem. This paper presents study the effect of types of curing, temperature, curing time and rest period. These parameters were studies like one variable parameter and other three are fixed parameter. One by one these parameters were finalize. The types of curing analyze with temperature optimization, rest period and curing time of geopolymer concrete. The type of curing like oven, accelerated, membrane, steam, wet and natural sun light (room temperature). The temperature differs like $60^{\circ} \mathrm{C}, 90^{\circ} \mathrm{C}$, $120^{\circ} \mathrm{C}$ and $150^{\circ} \mathrm{C}$. Once the temperature for type of curing is lock then proceed to curing time i.e. $6,12,18$ and 24 hours. At the end temperature, type of curing and curing time finalize then optimize the rest period or testing age of concrete. The rest period differ like 1, 3, 7, 14, 21, 28, 56 days. In this study these variable are to be analyze with the help of compressive strength of geopolymer concrete.
\end{abstract}

Keywords: Geopolymer concrete, type of curing, temperature, fly ash, curing time, rest period.

\section{INTRODUCTION}

In the geopolymer concrete, cement is totally replaced by fly ash (pozzolanic material) that is rich in silica and alumina and activated by alkaline liquids like sodium hydroxide and sodium silicate. Fly ash used as binder material of concrete. For the infrastructure development require huge quantity of concrete. It is well known fact that the production of OPC not only consumes significant amount of natural resources and energy but also releases huge quantity of carbon dioxide to the atmosphere. Therefore, it is necessary to find alternatives to make the concrete environment friendly with consideration of natural resources and atmospheric pollution.

Annually more than 100 million tons of fly ash is produced in India. The hectares of land required for dumping of wastage fly ash. On the other hand $\mathrm{CO}_{2}$ emission causes greenhouse gasses. Cement industries emits more $\mathrm{CO}_{2}$ in environment. If we use geopolymer concrete as an alternative to ordinary concrete which reduce greenhouse gasses as well fly as disposal problem. In geopolymer $100 \%$ fly ash used as binding material. For polymerization of geopolymer concrete require heat, due to this it is needy to study the types of curing and temperature variation of geopolymer concrete.

\section{RESEARCH REVIEW}

The oven heat curing of geopolymer concrete has been attempted by various researchers, but for curing of geopolymer concrete is quite difficult on site by using oven, so there is scope on types of curing which makes geopolymer concrete cure easily. The oven heat curing for geopolymer concrete is mostly used. The researchers studied only for different curing temperature in oven curing, but only few of them work on steam, membrane curing and no one work on accelerated curing, as well as comparison on steam, accelerated, membrane, natural and oven curing. So there is scope on method of curing of geopolymer concrete. Also researchers studied for different curing time like 6,12,18,24 and the optimum strength obtained at $18 \mathrm{hrs}$. of curing. The temperatures effect observed at $60^{\circ} \mathrm{C}, 90^{\circ} \mathrm{C}$, $120^{\circ} \mathrm{C}$ and $150^{\circ} \mathrm{C}$. The different type of curing i.e. Oven, Accelerated, Membrane and Steam curing were study and optimize. (Sandeep L. Hake et al, 2015).

The behavior of Fly ash based Geopolymer Concrete Solid Blocks and its Durability, the size of the block were adopted was $200 \mathrm{~mm}$ x $200 \mathrm{~mm}$ x $400 \mathrm{~mm}$. The brick were cast with fly ash to river sand, 
M-sand and eco-sand (silica sand) with the ratio of 1:2.5 by weight. Sodium hydroxide and Sodium silicate solution were used as the alkaline activators in geopolymer concrete. The binder solution consists of a combination of $\mathrm{NaOH}$ and $\mathrm{Na} 2 \mathrm{SiO} 3$ solution in the ratio of 1:2.5. The water/binder ratio is the ratio of solution $\left(\mathrm{NaOH}, \mathrm{Na}_{2} \mathrm{SiO}_{3}\right.$ and water) to fly ash. Totally 60 blocks were casted in this study under ambient curing. The blocks were cast with different types of sand with river sand, M-sand and eco-sand (silica sand). The experimental results obtained were compared with locally available Cement Solid Blocks (Sayyad and Patankar, 2013).

The effect of quantity of water, temperature duration of heating on compressive strength of fly ash based geopolymer concrete. $\mathrm{Na}_{2} \mathrm{Sio}_{3}$ solution containing $\mathrm{Na}_{2} \mathrm{O}$ of $16.45 \%, \mathrm{SiO}_{2}$ of $34.35 \%$ and $\mathrm{H}_{2} \mathrm{O}$ of $49.20 \%$ and sodium hydroxide solution with concentration of 13 Molar were used in geopolymer concrete as alkaline activators. Geopolymer concrete mixes were prepared with 0.35 solutions to processed fly ash ratio. Workability was measure by flow table apparatus. Geopolymer concrete cubes of $150 \mathrm{~mm} \mathrm{X} 150 \mathrm{~mm} \times 150 \mathrm{~mm}$ were cast. The temperature of curing was varied as $40^{\circ} \mathrm{C}, 60^{\circ} \mathrm{C}$, $90^{\circ} \mathrm{C}$, and $120^{\circ} \mathrm{C}$ for each period of 8,12 and 24 hours of oven heating and tested after a rest period of $1,2,3,7$ and 28 days after demoulding the concrete cube. Test results show that the quantity of water plays important role in balancing workability but not effect on strength. While higher temperature requires less duration of heating to achieve desired strength and vice versa. Author says that the rest period of 3 days is sufficient after heating at and above $90^{\circ} \mathrm{C}$ temperature (Subhash V. Patankar, 2013)

Geopolymer concrete is manufactured by cement fully replacing with processed fly ash which is activated by alkaline solutions like $\mathrm{Na}_{2} \mathrm{SiO}_{3}$ and $\mathrm{NaoH}$. Cubes of size $150 \mathrm{~mm}$ X $150 \mathrm{~mm} \mathrm{X} 150 \mathrm{~mm}$ were made at solution to fly ash ratio of 0.35 with 16 Mole concentrated sodium hydroxide solution. The specimens were cured in oven at $60^{\circ} \mathrm{C}, 90^{\circ} \mathrm{C}$ and $120^{\circ} \mathrm{C}$ for $6,12,16,20$ and 24 hour's duration. Test results show that the compressive strength increases with increase in duration and temperature of oven curing up to 24 hours (R. Anuradha, 2012).

The ratio for alkaline solution increases, the workability of mix goes on increasing. The study showed that the strength of geopolymer concrete can be improved by decreasing the water/binding and aggregate/binding ratios. It was observed that water influences the Geopolymerization process and the hardening of concrete. Inclusion of increased binder content enhances the Geopolymerization and affects the final strength. The optimum dosage for alkaline solution, which is used a geopolymer binder can be considered as 2.5, because for this ratio, the GPC specimens of any grade produced maximum strength results with compression and tension. The fly ash can be used to produce geopolymer binder phase which can bind the aggregate systems consisting of sand and coarse aggregate to form geopolymer concrete (GPC). Therefore these concretes can be considered as ecofriendly materials (Shankar H. Sanni et.al, 2013)

\section{MeTHOdOLOGY}

The geopolymer concrete was design for characteristics strength of M30 grade. The mix proportion for M30 grade (R. Anuradha, 2012). The cement is totally replaced by Pozzocrete fly ash P60. For the mixing of solution to fly ash ratio maintained as 0.35 for all types of curing. The alkali activators ratio i.e. sodium silicate to sodium hydroxide solution ratio is 2.5 . The rest period for GPC is of 7 days and curing time for concrete $18 \mathrm{hrs}$. The optimization of curing time and rest period was also study in this paper. The different types of curing were studied oven, steam, membrane, wet, natural sun light and accelerated curing. In this study, the fresh geopolymer concrete were found by proper mixing of dry solid and activators. The geopolymer concrete is made up of using fly ash, fine aggregate, coarse aggregate and alkaline liquid. The Pozzocrete P60 fly ash obtained from India Dirt Pvt. Ltd. The alkaline liquids are Sodium hydroxide $(\mathrm{NAOH})$ and Sodium Silicate $\left(\mathrm{Na}_{2} \mathrm{Sio}_{3}\right)$. The sodium silicate to sodium hydroxide ratio used is 2.5 and the solution to fly ash ratio is 0.35 . The pallets form of sodium hydroxide lab grade was obtained from market. The sodium silicate obtained from market in the liquid form. For preparation of $1 \mathrm{M}$ solution 40 grams of sodium hydroxide pellets of solid form was used. While we mix 40 grams pellets in one liter solution then we get $1 \mathrm{M}$ sodium hydroxide solution. Similarly, we prepare $16 \mathrm{M}$ solution for geopolymer concrete by adding 16 X $40=640$ grams sodium hydroxide pellets then we get $16 \mathrm{M}$ one liter sodium hydroxide solution. The heat evaluation rate is so high at the time of mixing pellets into water. Due to Sodium hydroxide solution was prepared one day prior to the casting of concrete cubes. 
In the laboratory, the dry mix of fly ash and aggregate were mixed in pan mixer. Then, required quantity of Sodium Hydroxide solution and sodium silicate solution with extra water mixed until homogeneous mix was formed. After making the homogeneous mix, workability test by slump cone and compaction factor is determined. Then, cubes of size $150 \mathrm{~mm} \mathrm{X} 150 \mathrm{~mm} \mathrm{X} 150 \mathrm{~mm}$ were cast in three layers as per standard process. Then after demoulding of cube these cube placed for curing of geopolymer concrete. The various methods are adopted for Oven, Steam, Accelerated and Membrane Curing at various temperatures like $60^{\circ} \mathrm{C}, 90^{\circ} \mathrm{C}$, and $120^{\circ} \mathrm{C}$. These cubes were placed at room temperature after curing up to the testing age. The testing age for cube will be assumed as 7 day which was fixed from past literature review. The processed and unprocessed types of fly ash analyze with the pallet and flex form of sodium hydroxide and sodium silicate. The processed fly ash contain the silicon and aluminum oxides in the low-calcium fly ash reacts with the alkaline liquid to form the geopolymer paste that binds the loose coarse aggregates, fine aggregates, and other un-reacted materials together to form the geopolymer concrete. The flex and pallets form of sodium hydroxide plays important role in polymerization the bond strength of flex form is less as compare to pallets form [14].

\section{RESULT AND DISCUSSION}

The initial parameters for geopolymer concrete were analyzing with the type of fly ash and the type sodium hydroxide activators. The unprocessed and processed fly ashes are optimizing with flex and pallets form of sodium hydroxide solution (Sandeep L. Hake, 2016). Then rest period, curing time, temperature and different curing condition of concrete were analyzed. This parameter were optimize one by one. While studying one parameter other two parameter lock with reference of past literature survey. Once the rest period lock then go for the curing time. The rest period and curing time optimize then study for temperature of geopolymer concrete.

\subsection{Analysis of fly ash with Pallets form of Sodium Hydroxide and Silicate}

The compressive strength for processed fly ash was study with temperature variation. It is observed that the strength for P100 is much higher than other but the cost of the P100 processed fly ash is much higher than other. As we consider for economy the characteristics strength of M30 grade concrete obtained for P60 grade of processed fly ash, so for the further study the P60 grade processed fly ash was used. As well unprocessed fly were analyze with pallets form of sodium hydroxide and procured from bhusawal, nashik \& beed thermal power plant at different temperature $80^{\circ} \mathrm{C}, 100^{\circ} \mathrm{C}$ and $120^{\circ} \mathrm{C}$ in figure 1.

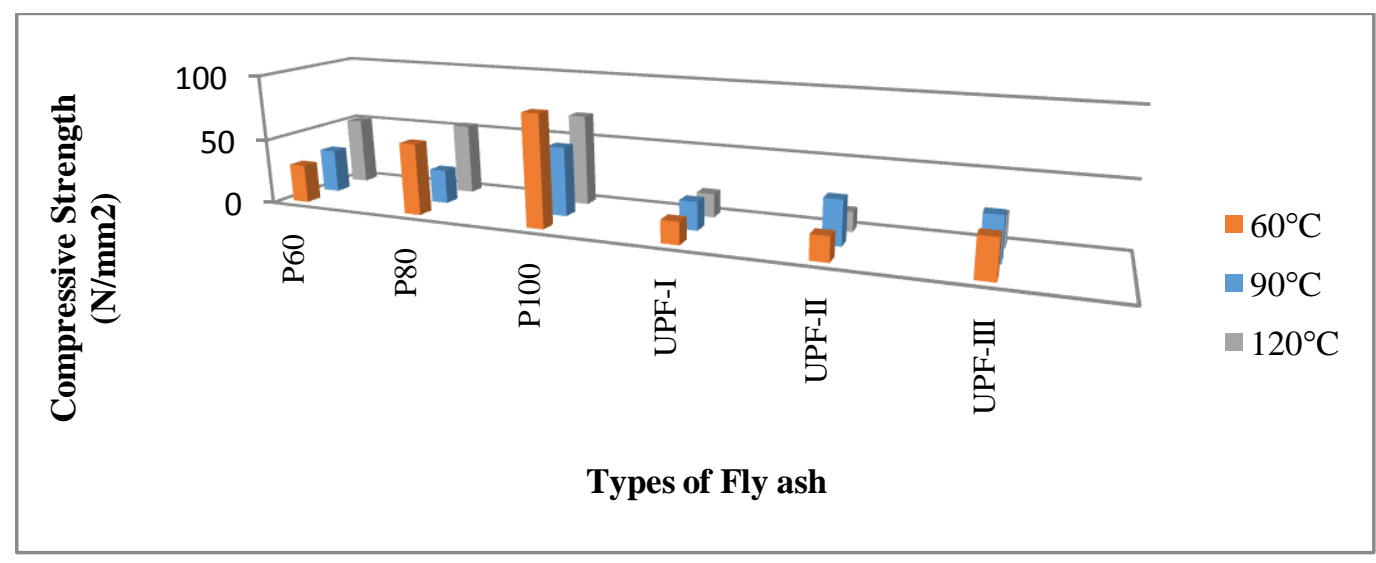

Figure1.Compressive Strength for pallets form of NaoH with types of fly ash

\subsection{Analysis of fly ash with Flex form of Sodium Hydroxide and Silicate}

The figure 2 shows the compressive strength behavior of processed and unprocessed fly ash. The effect of sodium hydroxide flex form on different types of fly ash was analyzed. As seen the strength for P100 is higher than the other but the cost of the fly ash is more as compare to other types of processed fly ash with consideration of economy the $\mathrm{P} 60$ type of processed fly ash is cheaper. These fly ash analyze with different temperature like $60{ }^{\circ} \mathrm{C}, 90{ }^{\circ} \mathrm{C}$ and $120^{\circ} \mathrm{C}$. 


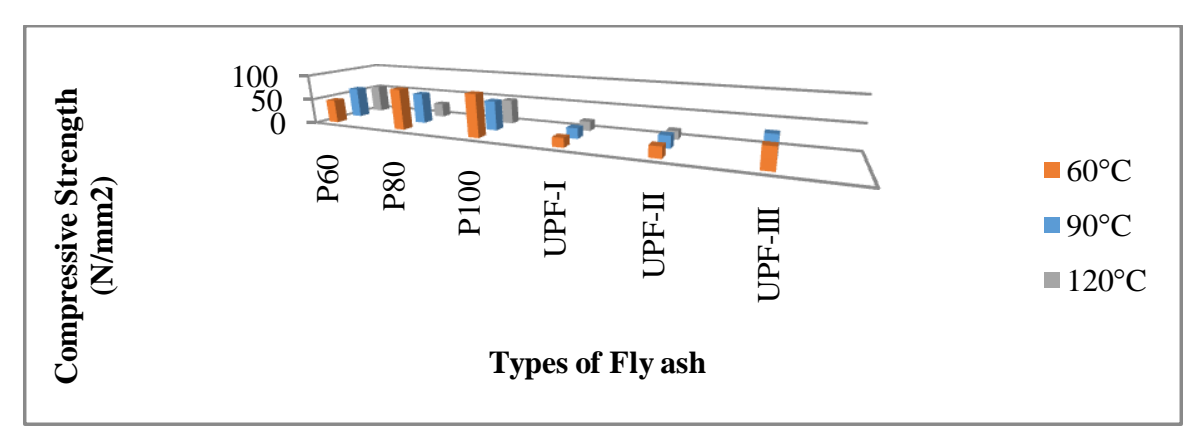

Figure2. Compressive Strength for Flex form of NaoH with types of fly ash

\subsection{Analyze Result For Rest Period}

The compressive strength of rest period for oven, steam, membrane, accelerated, wet and natural sun light curing at different temperature were analyzed. The rest period analyze for 1, 3, 7, 14, 21, 28 and 56 days. The temperature of oven and membrane curing maintained at $90^{\circ} \mathrm{C}$. The temperature for steam curing maintained at $120^{\circ} \mathrm{C}$ and also for accelerated curing it was maintained at $90^{\circ} \mathrm{C}$. The cubes were placed for room temperature for natural sun light curing as well as conventional curing method adopted for geopolymer concrete. As the rest period of concrete increases the compressive strength increases. The compressive strength at 28 and 56 days was not considerable. As we seen in graph 1 the 7 days rest period gives target strength.

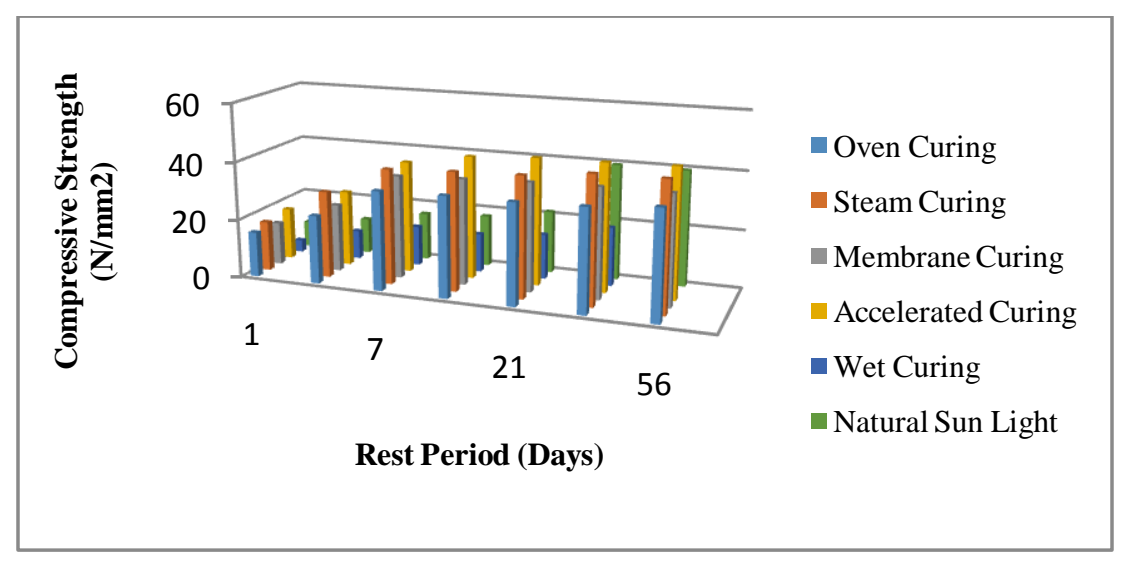

Figure3. Compressive Strength of GPC for curing and Rest Period

\subsection{Analyze Result For Curing Time}

The Compressive Strength of different types of curing with the help of curing time. The curing time varies with 6, 12, 18 and 24 hours. For higher temperature the curing time reduces. For oven and membrane curing the temperature optimize at $90^{\circ} \mathrm{C}$. But in case of steam it was optimize at $120^{\circ} \mathrm{C}$ and for accelerated curing it was $90^{\circ} \mathrm{C}$ for these temperatures the curing time optimize at 18 hours of all types of curing.

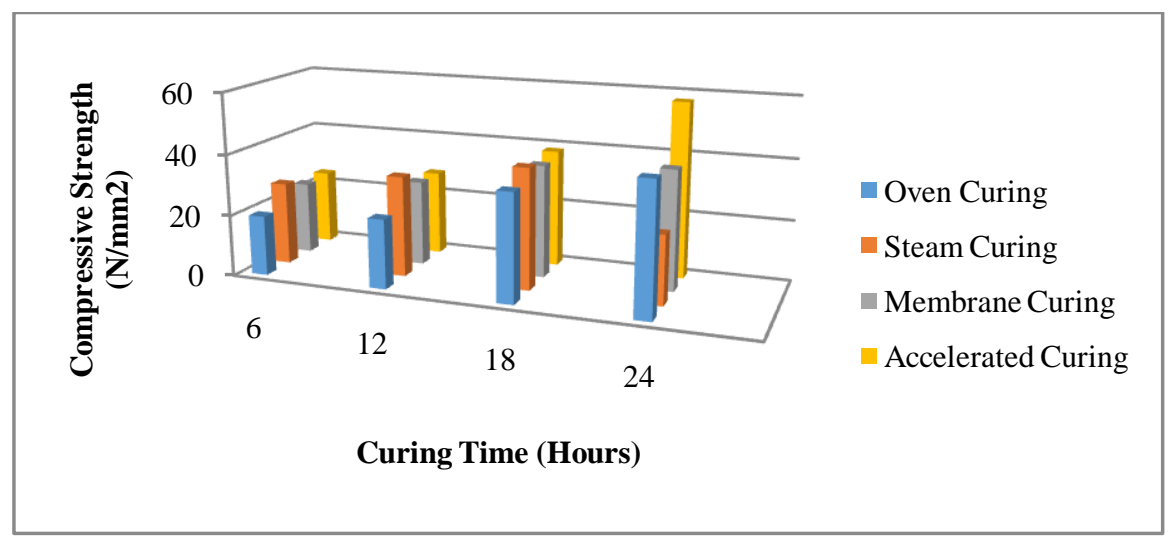

Figure4. Compressive Strength for different curing and its time. 


\subsection{Analyze Result for Temperature Variation.}

Figure 5 shows the effect of temperature variation and different type of curing on geopolymer concrete. In oven heat curing the temperature varies from $60{ }^{\circ} \mathrm{C}$ to $150{ }^{\circ} \mathrm{C}$ the optimum result we get at $90{ }^{\circ} \mathrm{C}$ with consideration of energy for heating.

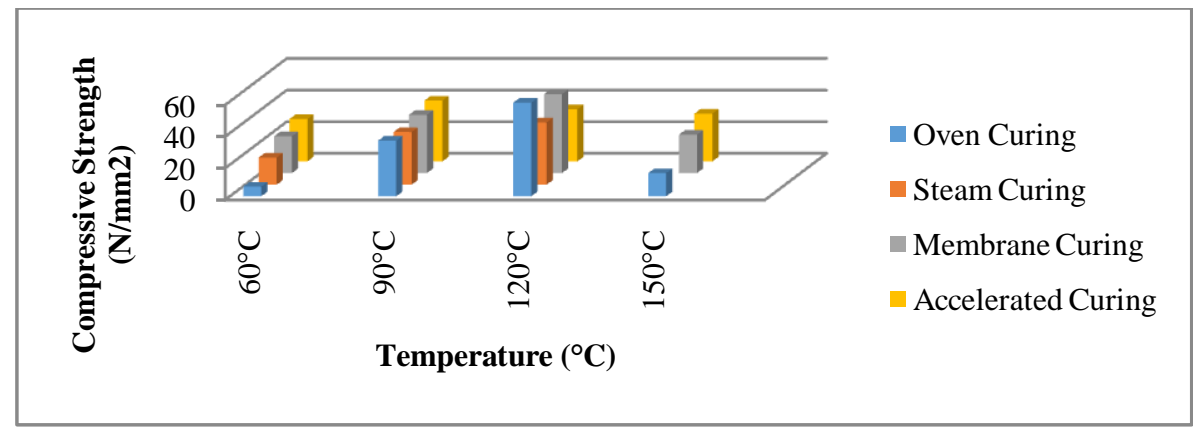

Figure5. Compressive Strength for temperature variation and curing type.

In Accelerated curing the effect of temperature on geopolymer concrete will show the optimum result at $120^{\circ} \mathrm{C}$. Also in membrane curing the effect of temperature varies from $60^{\circ} \mathrm{C}$ to $150^{\circ} \mathrm{C}$ the optimum result we get at $90^{\circ} \mathrm{C}$. In case of Steam curing the temperature optimize at $120^{\circ} \mathrm{C}$.

\section{CONCLUSION}

Based on investigation, the following conclusions have been drawn.

- The effect of pallets and flex form of sodium hydroxide activator on processed and unprocessed fly ash were analyzed and seen that the activators play important role for achieving the strength of geopolymer concrete.

- The types of fly ash specifically fineness affect the compressive strength of geopolymer concrete.

- In geopolymer concrete after 7 days the compressive strength of concrete achieves their target strength.

- It is seen that, in natural sun light curing target compressive strength achieves at 28 days. And also wet curing not suitable for geopolymer concrete.

- The compressive strength of geopolymer concrete achieves at $90^{\circ} \mathrm{C}, 120^{\circ} \mathrm{C}$ for oven and steam curing as well membrane and accelerated curing respectively.

- In short period of curing time i.e. $18 \mathrm{hrs}$ the polymerization of geopolymer concrete takes place and gives considerable target strength.

- It is observed that, the target compressive strength of concrete achieves at $90^{\circ} \mathrm{C}$ for oven curing and also after that the strength increases up to $120^{\circ} \mathrm{C}$ but at $150^{\circ} \mathrm{C}$ the strength of concrete losses his compressive strength due to overheating.

- In case of steam curing the compressive strength achieved at $100^{\circ} \mathrm{C}$ after that the strength increases but energy consumption for steam generation is more so it is optimize at $100^{\circ} \mathrm{C}$.

- In Accelerated Curing, the optimum result we will get at $90^{\circ} \mathrm{C}$ in this case the compressive strength suddenly decreases with increase in temperature.

- In case of Membrane curing the target compressive strength obtained at $90^{\circ} \mathrm{C}$ due to consumption of electricity this parameter optimize at $90^{\circ} \mathrm{C}$ while considering economy.

\section{REFERENCE}

[1] Sandeep L.Hake, Dr R. M. Damgir, "State of Art- Investigation of method of curing on geopolymer concrete" IOSR Journal of Mechanical and Civil Engineering (IOSR-JMCE), Volume 12, Issue 3 Ver. I (May. - Jun. 2015).

[2] Sandeep L.Hake, Dr R. M. Damgir, "Effect of temperature and curing type on geopolymer concrete" International Journal of Advance Research in Science and Engineering, Volume 5, Special issue 01, February 2016, ISSN 2319-8354.

[3] Atteshamuddin S. Sayyad and Subhash V. Patankar "Effect of Steel Fibers and Low Calcium Fly Ash on Mechanical and Elastic Properties of Geopolymer Concrete Composites", Indian Journal of Materials Science Volume 2013, Article ID 357563, 8 pages. 
[4] D. Hardjito and B. V. Rangan development and properties of low-calcium fly ash-based geopolymer concrete", research report ge 1 faculty of engineering curtin university of technology perth, australia 2005.

[5] S. E. Wallah and b. V. Rangan "low-calcium fly ash-based geopolymer concrete: long-term properties", Research Report GC 2 Faculty of Engineering Curtin University of Technology Perth, Australia 2006.

[6] Subhash v. Patankar, Sanjay s. Jamkar, Yuwaraj m. Ghugal, "Effect of fly ash fineness on workability and compressive strength of geopolymer concrete" The Indian Concrete Journal, April 2013.

[7] Subhash v. Patankar, Sanjay s. Jamkar, Yuwaraj m. Ghugal, "Effect of Water-to-Geopolymer Binder Ratio on the Production of Fly ash Based Geopolymer Concrete" International Conference on Recent Trends in engineering \& Technology 2013 (ICRTET'2013) Organized By: SNJB's Late Sau. K. B. Jain College of Engineering, Chandwad, 2013.

[8] Subhash v. Patankar, Sanjay s. Jamkar, Yuwaraj m. Ghugal, "effect of water-to-geopolymer binder ratio on the production of fly ash based geopolymer concrete" international journal of advanced technology in civil engineering, ISSN: 2231 -5721, volume-2, issue-1, 2013.

[9] Sub hash V. Patankara, Yuwaraj M. Ghugal, Sanjay S. Jamkar "Selection of Suitable Quantity of Water, Degree and Duration of Heat Curing for Geopolymer Concrete Production" Proceedings of 3rd International Conference on Recent Trends in Engineering \& Technology (ICRTET'2014).

[10] Sunilaa George, Dr.R.Thenmozhi "Flexural Behaviour of Activated Fly Ash Concrete" International Journal of Engineering Science and Technology (IJEST), Vol. 3 No. 10 October 2011.

[11] Prof. P. K. Jamdade and Prof. U. R. Kawade, "Evaluate Strength of Geopolymer Concrete by Using Oven Curing", IOSR Journal of Mechanical and Civil Engineering (IOSR-JMCE), e-ISSN: 2278-1684, p-ISSN: 2320-334X, Volume 11, Issue 6 Ver. V, November-December 2014, pp. 63-66.

[12] Keun-Hyeok Yang, Jae-Sung Mun and Ho Lee, "Workability and Mechanical Properties of Heavyweight Magnetite Concrete", ACI Materials Journal Disc. 111-M23, May-June 2014, pp. 317-322.

[13] Shankar H. Sanni, R. B. Khadiranaikar, "Performance of Alkaline Solutions on Grades of Geopolymer Concrete" IJRET: International Journal of Research in Engineering and Technology 2013, eISSN: 23191163.

[14] R. Anuradha, v. sreevidya, r. venktasubramani and B. V Rangan "Modified guidelines for geopolymer concrete mix design using Indian Standards" Asian Journal of Civil Engineering, Vol 13 No 3, 2012, page 353-364.

[15] Sandeep L. Hake, Dr R. M. Damgir "Evaluation on Types of Fly Ash and Alkaline Activators of Gpc", International Conference on Innovative Trends in Engineering Research, ISSN: 2394-3696, 2016, PP-171176.

[16] Sundar Kumar S., Vasugi J., Ambily P. S. and Bharatkumar B. H., "Development and Determination of Mechanical Properties of Fly Ash Slag blended Geopolymer Concrete", International Journal of Scientific \& Engineering Research, ISSN : 2229-5518, Volume 4, Issue 8, August-13.

[17] Mohammed Rabbani Nagral, Tejas Ostwal and Manojkumar V Chitawadagi, "Effect of Curing Temperature and Curing Hours on the Properties of Geopolymer Concrete", International Journal of Computational Engineering Research (IJCER), ISSN (e) : 2250 - 3005, Volume 4, Issue 9, September14.

[18] Herbert Sinduja J, Sakthieswaran N and Shiny Brintha G, "Review on Geopolymer Concrete with Different Additives", International Journal of Engineering Research (IJOER), Volume 1, Issue 2, May-15, pp. 21-31.

[19] Benny Joseph and George Mathew, "Influence of Aggregate Content on the behavior of Fly Ash based Geopolymer Concrete”, Scientia Iranica A, Volume 19, No. 5, 2012, pp. 1188-1194.

[20] J. Amirtharaj Praveen, P. Senthilkumar, J. Sridhar and S. Nickson, "A Comparative Study of Alkali Activated Slag and Fly Ash based Geopolymer Concrete", International Journal of Innovative Research in Science, Engineering and Technology, ISSN (Online) : 2319-8753, ISSN (Print) : 2347-6710, Volume 4, Issue 10, October-15, pp. 10151-10156.

Citation: S. L. Hake et.al, "Effect of Alkaline Solution on Different Types of Fly Ash of GPC. ”, International Journal of Constructive Research in Civil Engineering, 4(2), pp. 21-26. DOI: http://dx. doi.org/10.20431/ 2454-8693.0402004

Copyright: (C) 2018 S. L. Hake et.al., This is an open-access article distributed under the terms of the Creative Commons Attribution License, which permits unrestricted use, distribution, and reproduction in any medium, provided the original author and source are credited. 